\title{
Os CAMINHOS DA IMPROVISAÇÃO
}

\author{
Maria Luiza Ramos \\ UFMG
}

Não éramos apenas nós, os outros. Os horizontes eram outros. As leis eram outras.

Quando foi criada a Faculdade de Filosofia, Ciências e Letras, ainda vigorava o Curso Ginasial em cinco anos, que logo no ano seguinte se reestruturou como Ginasial, em quatro, e Clássico e Científico, em três. Como apenas as escolas tradicionais Medicina, Direito e Engenharia - ministravam dois anos pré-universitários, o ingresso nas escolas novas se fazia diretamente, sem qualquer curso preparatório. Aos quinze anos, portanto, entrava-se para a Universidade, mas como me aumentaram a idade para o exame de admissão ao ginásio, ainda no Rio de Janeiro, foi com catorze que cursei aqui o primeiro ano de Arquitetura. Eram poucos os estudantes, e eu, a única aluna. Com desenho pouco e matemática muita, desisti antes das provas finais, por ter tido notícia de que já estava funcionando um curso de Letras na Faculdade de Filosofia.

E o corpo docente desse curso, como se compunha? No consenso, pelo menos assim foi: ninguém melhor do que $\mathrm{X}$ para esta cátedra; $\mathrm{Y}$ é o ideal para aquela e $\mathrm{Z}$ é perfeito para aquela outra. E eram mesmo! Além da competência, era de admirar-se o entusiasmo, o desprendimento desses mestres idealistas. Porque não havia remuneração. No faz-de-conta de que se tratava de um trabalho, cumpriam as suas obrigações com seriedade.

Bem, acho que já é hora de dizer que o meu curso era o de Letras Clássicas, tendo eu ingressado em 1942, na segunda turma, portanto, da nova Faculdade. Já tive outras ocasiões de relembrar esse tempo: No Memorial, por exemplo, que escrevi para prestar o concurso de Titular, e no discurso em que agradeci o título de Professora Emérita da Faculdade de Letras da UFMG. Essa cerimônia teve para mim um sentido todo especial, pelo fato de ligar as duas coisas que tive de graça em minha vida de muito batalhar: o Curso de Letras Clássicas e as honras desse título.

É que o ensino era pago, e, como eu não tinha recursos, fui pedir ao Diretor, então o Prof. Braz Pelegrino, que me deixasse estudar de graça. Não havendo sistema de bolsas, era mesmo no favor pessoal que tudo se decidia. Pena é que, ao se tornar público, o ensino chamou-se logo "gratuito", e, por uma herança paternalista de nossa cultura, o governo passou a ser autor de benesses - mentalidade que permanece até hoje, sem que se associe o pagamento de impostos à responsabilidade pela educação do povo.

Mas eu estava falando de uma improvisada Faculdade de Filosofia, em que todos os cursos funcionavam conjuntamente em umas poucas salas do Instituto de Educação. Assistia-se a uma aula aqui, a outra ali, sem fazer distinção entre cursos, na medida em que os horários vagos permitiam. A grande novidade, porém, era o grego, que conquistara a minha predileção. O catedrático seria o Professor Cláudio Brandão, mas durante todo o meu curso quem deu as aulas foi o Professor José Altimiras, que nos transmitia com 
entusiasmo e dedicação o que aprendera em tempos de Seminário. Ao contrário do latim, que os professores supunham que a gente já conhecesse - pois nos cinco anos ginasiais, além de todas as matérias que passaram depois para o Clássico e Científico, ainda se estudava inglês, francês e latim - a as aulas de grego começavam com o alfabeto e a primeira declinação. Assim, despretensiosamente e com irrepreensível assiduidade, o Professor Altimiras nos proporcionava um estudo sistemático que em pouco tempo se mostrou eficaz: ao surgir a exigência de um exame para o ingresso nos cursos universitários, eu, com um ano apenas à frente dos candidatos, é que fui encarregada das aulas preparatórias de grego, no cursinho de férias que fazia as vezes de um vestibular. No ano seguinte, no início, pois, do meu terceiro ano, o Professor Altimiras me indicou também para substituí-lo no Curso Clássico recém-criado no Colégio Marconi. Seria por pouco tempo apenas, já que o seu horário não lhe permitia aceitar imediatamente o convite que lhe fora dirigido. Mas os acertos não se concretizaram e acabei ministrando as aulas de grego durante seis anos, tendo elaborado os programas para as três séries do curso, até que ele foi extinto do currículo. Foi para mim uma experiência extraordinária, porque, me valendo de todos os livros que encontrava, pude ir bem além dos conhecimentos que tinha recebido nas aulas, tanto no exercício de traduções quanto no estudo da literatura. Por esse tempo, já o diretor - o Professor Arthur Versiani Velloso - a me confiara turmas de Português, e também o Professor Mário Casassanta me indicara para substituí-lo no Colégio São Paulo, de modo que, de repente, eu já era professora com grandes responsabilidades, principalmente a de ocupar o lugar dos meus mestres.

O clima geral, portanto, era o da improvisação. E mesmo fora da instituição, tudo se processava mais ou menos assim. Eis um exemplo, que vou citar pelo efeito multiplicador que teve na minha carreira universitária. Eu escrevia artigos para o Diário de Minas, muitos deles sobre literatura grega, na esperança de me tornar Assistente dessa matéria, pois, com o reconhecimento da Faculdade, os professores já eram então remunerados e havia cargos a preencher. Como o Professor Cláudio Brandão, que seria o catedrático quando da fundação da Faculdade, só assumiu depois disso, não fui aluna sua, mas procurei-o pela experiência que já tinha nesses anos de ensino de grego, e ele me disse que havia então outros pretendentes; que ele aplicaria uma prova e consideraria os títulos. Entretanto, pouco depois o Professor Brandão, sem prova alguma, indicou uma aluna sua, ainda estudante, e foi para a Europa. Isto explica a mudança que se deu em meu horizonte acadêmico. Passei a me dedicar à literatura brasileira, aos temas atuais, e, com uma produção regular nos periódicos, não só daqui, mas também do Rio - no Letras e Artes, do Correio da Manhã, que não mais existe - e de São Paulo, no Estado de S. Paulo, acabaram me convidando para dirigir o Suplemento Literário do Diário de Minas, um jornal daqui que fechou há muito tempo.

Não havia nenhum curso de jornalismo, nem de comunicação em Belo Horizonte e passei por novo período de improvisação. Era uma corrida da redação às oficinas, única maneira de aprender na marra o ofício, em que eu fazia de tudo: artigos, entrevistas, movimento editorial, até ilustrações, para dar conta das oito páginas semanais, que além das três de literatura, contavam com uma de cinema, outra feminina, uma infantil e ainda outra de assuntos agrícolas. Para essas havia quem me trouxesse o material, mas a seleção e a paginação eram de minha responsabilidade. Afinal, com uma excelente 
equipe de colaboradores, como Francisco Iglesias, João Dornas Filho, Affonso Ávila, Amaro Xisto de Queirós, Fritz Teixeira de Sales, Fábio Lucas, Rui Mourão e outros escritores mineiros, nos dois anos em que dele me encarreguei, o Suplemento Literário do Diário de Minas era respeitado mesmo fora de Minas, enquanto eu continuava com a minha carteira profissional de início de carreira - e é claro, o salário de repórter.

Tudo, porém, acaba tendo um sentido. É que, tendo se aposentado o professor de literatura brasileira, abriu-se na Faculdade uma vaga para essa cátedra. Pós-graduação, não havia. A inscrição se fazia por "notório saber" e, no meu caso, se o saber podia ser pouco, era, pelo menos, notório. Meus artigos tinham boa acolhida e, do ponto de vista do magistério, eu havia também sido convidada para compor o corpo docente do recémcriado Colégio Municipal de Belo Horizonte, onde comecei lecionando latim e logo passei para o português.

Com uma tese intitulada Psicologia e estética de Raul Pompéia, enfrentei esse novo desafio, concorrendo com um professor que já ocupava, interinamente, a cátedra de literatura portuguesa. Dos cinco membros da banca examinadora, obtive apenas duas indicações, tornando-me, pois, livre-docente. Essas indicações, porém, tiveram para mim um valor qualitativo e muito me honraram, porque partiram dos Professores Cyro dos Anjos e Guilhermino César, que, além de serem os dois professores que efetivamente lecionavam literatura - portuguesa e brasileira, respectivamente - eram escritores de reconhecido mérito.

E como surgiu aquela psicologia no título da tese? Claro que não havia, igualmente, nenhum curso de psicologia na universidade. Mas eu fizera alguns anos antes um concurso do DASP para inspetor de ensino, e, como uma das provas era "Psicologia e Pedagogia", voltadas para o adolescente, estudei tudo o que se referia ao programa, e, tendo tomado gosto, li muito mais do que era preciso, o que resultou num, para mim surpreendente, primeiro lugar nacional. Sem qualquer orientação, passei da psicologia à psicanálise, decidindo então me analisar, porque, segundo os livros, era condição para lidar com essa matéria. A psicoterapia não era ainda uma prática em nosso meio, e submeter-se a análise era coisa pra doido. Guardei então segredo disso.

Sucede que, do mesmo modo que a passagem pelo jornal, essa incursão na psicanálise muito me valeu. É que o dr. Leão Cabernite tinha planos de fundar uma clínica e deu um caráter didático à minha análise, para que eu me ocupasse da terapia infantil. Além do que eu já havia lido, tive, então, um estudo sistemático, com especializada bibliografia. Entretanto, esse trabalho se interrompeu depois de cerca de dois anos, por causa da sua mudança para o Rio. Ao escrever a minha tese, alguns anos depois, foi ao dr. Paulo Saraiva, psiquiatra, que recorri, pois havíamos tido um cordial contato através do Suplemento que eu dirigira, e no qual ele publicava vez por outra um artigo. Com muito boa vontade, me emprestou livros e, principalmente, deu um tranquilizador aval ao trabalho concluído.

Raul Pompéia fora uma sugestão do escritor Fábio Lucas, com quem eu me casara, e essa obra foi lembrada não só por ser muito reduzida a sua bibliografia crítica, mas também pelas suas implicações psicológicas, em que a personagem central era um adolescente. Dada a precariedade de nossas bibliotecas, passei quinze dias praticamente dentro da Biblioteca Nacional, no Rio de Janeiro, onde, além do trabalho de pesquisa, 
fiz também as vezes de xerox. É que, não tendo sido ainda inventada essa maravilha tecnológica, a gente tinha de fazer à mão fichas e mais fichas! Munida de um vasto material, em grande parte original, colhido em jornais da época, e recorrendo diretamente a modernas teorias críticas que até então eu via discutidas exclusivamente no plano teórico, escrevi uma tese que resultou não apenas na livre-docência, mas em dois prêmios - um da Prefeitura Municipal de Belo Horizonte, outro da Academia Mineira de Letras, além de preciosas referências de Otto Maria Carpeaux, Lúcia Miguel Pereira e Eugênio Gomes. Apesar de tudo, fiquei ainda dois anos fora da Faculdade, porque o professor que obtivera a cátedra de Literatura Brasileira acumulou-a com a de Literatura Portuguesa, que já exercia.

Somente quando a Teoria da Literatura entrou para o currículo, em 1961, é que fui chamada para ministrar essa matéria nova, que nem eu nem ninguém tinha cursado em nossa Faculdade. É certo que na prova escrita daquele concurso eu já tinha feito uso da Teoria Literária, de Wellek e Warren, um texto então recente, que aqui nos chegou em tradução para o espanhol. Foi esse o grande desafio que me levou novamente a vasculhar bibliografia, que contava por essa época com um único título em português: a Teoria da Literatura, de Soares Amora.

Sob a alegação de que as cátedras iam ser extintas, e por uma distorção acadêmica, essa matéria, que seria básica e dada em um ano para todos os cursos de letras, foi instituída como disciplina, e de Filologia Românica! Pois além de ter tido sucesso esse ano letivo introdutório, programou-se pouco depois a matéria também para o último ano, e, com o sistema de créditos, diversificou-se ela em vários cursos, atendendo à demanda dos estudantes, até que se impôs, mais tarde, como Departamento, com mais de uma dezena de professores, quase todos doutores, os quais passaram a ministrar cerca de cinquenta disciplinas, incluindo-se aí a Semiótica.

A vinculação da Teoria da Literatura com a Filologia Românica era estritamente burocrática e nunca houve, portanto, qualquer subordinação de ordem acadêmica. Como regente de Teoria da Literatura, eu era responsável não só pelos programas, como pela indicação e a orientação de auxiliares de ensino, e logo de assistentes, pois não havia concursos. Mais uma vez eu contava com um excelente grupo de colaboradores, tanto assim que, ao ser necessário indicar um assistente, improvisei um concurso interno, informal, entre os alunos que mais se destacavam. Que essa foi uma medida feliz comprovou-a a professora Eneida Maria de Sousa, que, tendo feito logo depois mestrado na PUC/Rio, doutorou-se em Paris e, com uma relevante produção intelectual, veio a tornar-se professora emérita de nossa Faculdade.

Com uma bibliografia escassa e em grande parte inaccessível aos alunos por ser em língua estrangeira, desenvolvi um trabalho próprio a partir da obra do polonês Roman Ingarden, de que havia em nossa biblioteca uma tradução em alemão - Das literarische Kunstwerk - A obra de arte literária. Para isso contei com a colaboração da Professora Tarcísia Múcia Lobo Ribeiro, do Curso de Letras Germânicas, pois não eram suficientes os meus conhecimentos de alemão para a leitura de um livro que, mais tarde, veio a ser considerado de estilo "labiríntico" por outros tradutores. Contei também com a colaboração do Professor Moacyr Laterza, do Departamento de Filosofia, uma vez que a obra de Ingarden fundamentava-se na fenomenologia de Husserl. 
Havia muita cooperação entre os colegas. Além das aulas da Frau Kux, que me reforçavam o curso de extensão que eu fazia em língua alemã, eu frequentava também as do Professor Peter Magnani, que lecionava inglês. Supríamos, assim, as nossas lacunas acadêmicas, o que nos proporcionava um cordial intercâmbio.

Tendo o Professor Laterza me franqueado a sua biblioteca, em que filosofia e literatura se confundiam, propus-lhe fazermos um seminário interdisciplinar sobre o tema fenomenologia - o primeiro que conseguiu atravessar a grossa laje que separava o sétimo do oitavo andar do velho prédio da rua Carangola, em que nossas aulas se realizavam. Lembro-me, com satisfação, de que participaram desse trabalho dois alunos que vieram a ter grande projeção em nossa Universidade e mesmo fora dela: a Professora Sônia Viegas, que infelizmente nos deixou muito cedo, deixando também um belo exemplo de dedicação ao trabalho intelectual, e o Professor Mário Alberto Perini, este, que se tornou PHD em Linguística pela Universidade do Texas.

Dedicando-me, pois, à fenomenologia, escrevi um texto que no Concurso Nacional de Literatura, promovido pelo Instituto Nacional do Livro, mereceu em 1968 o Prêmio Mário de Andrade, e, com o título Fenomenologia da obra literária, foi publicado nesse mesmo ano pela Editora Forense, do Rio de Janeiro.

Do ponto de vista administrativo, entretanto, não tive semelhante êxito. Quando saiu uma lei efetivando quem estivesse havia cinco anos em exercício de cargo, todos os colegas que se encontravam na cátedra como substitutos se tornaram titulares, enquanto eu continuei como adjunto, pelas circunstâncias em que a Teoria da Literatura havia sido criada. Tal condição se estendeu por vinte anos, pois, nesse período, não houve na Faculdade nenhum concurso para professor titular. Aliás, no princípio dos anos setenta, quando regressei de um período de dois anos nos Estados Unidos, destinaram-se quatro vagas à Faculdade, as quais foram alocadas no Departamento de Vernáculas, em que a Teoria da Literatura ainda figurava. Tendo a Câmara decidido que, por razões econômicas, os concursos se fariam por etapas - primeiro o de duas vagas para assistente, depois o de adjunto e por último o de titular - quando chegou a vez desse concurso, para o qual eu estava me preparando, a vaga tinha sido remanejada para outra Unidade, com a alegação de que não havia sido utilizada. Somente anos depois, quando eu já tinha decidido me aposentar, a Reitoria destinou afinal uma vaga de titular para a Faculdade de Letras. Reivindiquei-a por uma questão moral, para não sair da instituição na mesma situação em que havia entrado. Desço a esses pormenores porque a eles se deve o fato de eu ter levado vinte anos para chegar ao final da carreira universitária, tendo-a iniciado já como livre-docente, por concurso.

A minha ida para o exterior, em meados de 1970, não teve uma motivação acadêmica, a não ser indiretamente. Tendo o Professor Fábio Lucas sido aposentado pela Junta Militar, do mesmo modo que muitos outros professores, e até mesmo reitores da UFMG, acompanhei-o, com os quatro filhos, aos Estados Unidos, onde ele tinha uma proposta de trabalho na Universidade de Minnesota. Para isto, a Faculdade de Letras concedeu-me uma licença, a fim de que eu aproveitasse essa oportunidade para fazer cursos pós-graduados, mesmo não obedecendo a um programa acadêmico determinado.

Assim, além de dois cursos trimestrais da Universidade de Minnesota - um de "Literatura hispano-americana", outro de "Literatura e outras artes" - fiz dois cursos no 
semestre em que passei na Universidade de Princeton - "A esteira da Odisséia" e "Bach e Camões - o Barroco" - e ainda outro curso na Universidade do Texas - "Símbolo, mito e arquétipo" - para onde nos havíamos sucessivamente transferido. Apesar das circunstâncias excepcionais de minha admissão aos cursos, em caráter de ouvinte recomendada pelo meu orientador, muito aproveitei dessa experiência e pude repassála em minha instituição. É que, ao retornar, em meados de 1972, inteirei-me de que o projeto do Mestrado em Letras estava na iminência de indeferimento, por abranger várias modalidades de curso.

Eu era então chefe do Departamento de Vernáculas e contava com o regime de dedicação exclusiva, o que era uma raridade fora dessa condição, pois os trabalhos de pesquisa não eram reconhecidos e se faziam em fins de semana, à noite, enfim, no espaço que deveria ser o de lazer do professor. Isto se devia, em grande parte, ao fato de que, apesar dos muitos benefícios que tivemos com a criação da Faculdade de Letras graças, principalmente, à determinação e à visão acadêmica da Professora Ângela Tonelli Vaz Leão - ao se desmembrar a antiga Faculdade de Filosofia deparamos de início com dificuldades relativamente à classificação de nossos cursos na comunidade universitária. A tendência era nos situar ao lado de Música e Belas Artes, que têm objetivos próprios no campo da arte. Minimizava-se, assim, o caráter científico dos estudos linguísticos e literários, o que mais tarde veio a ser corrigido.

Mas eu falava de um Mestrado a instituir, e, para salvá-lo, idealizei um projeto de reestruturação desse curso, para o qual convidei colegas com experiência tanto em cursos de pós-graduação realizados no Rio e no exterior, quanto em doutoramento pelos moldes anteriores, e mais um representante dos alunos. Para todos solicitei regime de dedicação exclusiva, o que foi motivo de mofa. Um colega chegou a me dizer: "- Pode pôr o meu nome, que isto não vai sair mesmo." Pois saiu. Um trabalho bem feito merece credibilidade, e era o que tínhamos feito.

Deixei a chefia para integrar o grupo e, da minha experiência no exterior, trouxe subsídios para a literatura comparada, tendo logo me encarregado de dois cursos nessa área - um, "Literatura e outras artes", conforme inspiração de aulas tidas na Universidade de Minnesota; outro de "Fundamentos de literatura comparada: a tradução", a partir dos cursos feitos no semestre em que passei em Princeton, com uma concepção de tradução inteiramente nova, que causou polêmica junto aos nossos cursos tradicionais, principalmente na área de francês. Do Texas trouxe inspiração para um curso que denominei "O elemento mítico da obra literária", com uma fundamentação antropológica ampla, diferente daquela que então se fazia entre nós, circunscrita ao estruturalismo lévistraussiano.

Cada um de nós deu, portanto, a sua colaboração, e, tendo saído o projeto, o curso também saiu. Mais tarde, quando se programava o Doutorado, fiz também a minha parte, mudando o rumo de uma pesquisa sobre o expressionismo, que já se havia iniciado em Paris, com bolsa de pós-doutorado do CNPq, para estendê-la a Munique, onde trabalhei com o expressionismo alemão, apoiada por uma bolsa do DAAD ("Deutscher Akademischer Austausch Dienst” - Serviço Alemão para o Intercâmbio Acadêmico), que me foi oferecida pelo Goethe Institut, onde eu também havia estudado. Com o título "O percurso dos discursos", contribuí não só com relação ao currículo, em que essa 
disciplina passou a figurar, mas na constituição do corpo docente de que, infelizmente, só vim a participar muitos anos depois, como visitante. É que, ao completar um ano após aquele em que estivera na Europa, aposentei-me, contando com trinta e três anos de serviço público, sendo que já vigorava a lei que exigia apenas vinte e cinco.

Mas a minha atividade universitária não parou por aí. Além de orientar teses e dissertações, como pesquisadora do $\mathrm{CNPq}$ dei continuidade ao trabalho que vinha desenvolvendo no campo interdisciplinar literatura/psicanálise, desde que a obra de Lacan se impôs aos estudos literários, motivando, inclusive a releitura de Freud. Continuei publicando artigos, sobretudo em revistas da nossa Faculdade, como Ensaios de Semiótica, que ajudei a criar quando de minha passagem pela Diretoria, participando também de congressos e de bancas examinadoras. Fui convidada a dar cursos sobre inconsciente e linguagem em instituições psicanalíticas, defendendo sempre a necessidade de uma interação mais efetiva desses estudos em termos de currículo, pois não se pode conceber psicólogos, e principalmente psicanalistas, que não tenham conhecimentos de linguística, retórica e sobretudo poética. Nesse sentido, escrevi um texto - Os avessos da linguagem premiado em 1988 no Concurso Nacional de Literatura da Prefeitura Municipal de Belo Horizonte e publicado por essa instituição.

Relendo agora esta longa rememoração, que está sendo para mim algo como um pensar alto, vejo que deixo aqui uma imagem do que foi a minha Faculdade de Filosofia, ou a minha Faculdade de Letras, bem diversa, por certo, desta vivenciada pelos colegas que me sucederam. Fico feliz ao ver o extraordinário progresso que houve em todos os setores da vida acadêmica: os cursos de pós-graduação, com orientadores aqui e no exterior; o apoio à pesquisa; os concursos frequentes; o enriquecimento das bibliotecas e dos recursos materiais - a mudança para o campus, auditórios, gabinetes, telefones, computadores - tudo isto que parece conto de fadas aos olhos daquela época em que lecionei, por exemplo, História da cultura artística e literária no antigo curso de jornalismo, do Departamento de Filosofia, sem contar sequer com um projetor de slides, que eu tinha de levar de casa.

Sinto-me, porém, no dever de expressar uma grande preocupação: o abismo que separa a Universidade do ensino de segundo grau. Seria excelente se o fluxo crescente de estudantes para os cursos de pós-graduação, com vistas ao magistério superior, tivesse de fato uma motivação intelectual e não se devesse também a questões de ordem econômica. É, porém, compreensível que os formandos vejam na pós-graduação a possibilidade de bolsas, e, desestimulados pelos baixos salários dos colégios, particularmente os da rede pública, optem por esse substitutivo salarial. Com isto, vamos formando doutores que a Universidade, certamente, não tem condição de absorver, enquanto faltam professores para o ensino médio. A juventude tem o direito a bons profissionais, pós-graduados, mas, com o aviltamento das condições de trabalho do segundo grau, está se criando uma elitização universitária que acaba por minimizar a imagem profissional daqueles que a esses cursos não podem recorrer. E o que me espanta é ver que, vez por outra, se reacende a antiga questão de separação de cursos - magistério para um lado, pesquisa para o outro - o que me parece suicídio acadêmico, uma idéia contra a qual sempre me bati durante toda a minha permanência na Faculdade. Não existe bom professor que não seja ao mesmo tempo pesquisador. É preciso evitar que os 
futuros mestres da nossa juventude se reduzam à condição de repetidores de livros, quando não de aulas - muitas vezes mal anotadas - transformando-se em enlatados ambulantes, que transmitem o que foi gravado na memória, incapazes de criar o seu próprio material didático. É claro que, por ser uma questão conjuntural, a responsabilidade disso não cabe à Universidade. Mas a ela cumpre uma participação mais efetiva junto à cúpula da política educacional do país, no sentido de se reverter esse quadro sombrio.

E é nesse clima, que ora me contagia, que, relendo o Memorial que escrevi para submeter-me ao concurso de titular, surpreendeu-me um certo sentimento de culpa que transparece aqui e ali, em função das condições improvisadas dos encargos que eu assumira. Creio, porém, que esse sentimento se deve ao fato de termos sido condicionados por uma relação espaço-tempo em que o agora resulta necessariamente de um antes e é fator de todo depois, como se fôssemos minimáquinas feitas à semelhança da grande "máquina do mundo", em que a ordem é o fio condutor, em mecânica linearidade. O conhecimento adquirido numa educação sistemática é, sem dúvida, de fundamental importância. Entretanto, a existência não se circunscreve aos limites de uma consciência individual, e é na condição caótica do presente que se abre espaço para a criatividade, num desafio ao determinismo das relações locais. De nossa entrega ao imprevisível resultam os nossos atos. Chame-se a isto coragem, ou tenha o nome que tiver. Esse mesmo não me parece muito feliz, pois se aplica a emoções inteiramente contrárias. Quando, por exemplo, deixei a diretoria da Faculdade de Letras, por me recusar a obedecer à Polícia Federal, que me intimara a fornecer-lhe endereços de um grupo de alunos e exalunos nossos, muita gente comentou a minha "coragem". No universo dos meus valores, entretanto, coragem é o que seria necessário para o cumprimento daquela ordem. 